\title{
Avaliação da aprendizagem como ato pedagógico: o erro construtivo
}

\author{
Evaluation of learning as a pedagogical act: the constructive error \\ Evaluación del aprendizaje como acto pedagógico: el error constructivo
}

Recebido: 14/01/2022 | Revisado: 19/01/2022 | Aceito: 25/01/2022 | Publicado: 26/01/2022

\author{
Klesia de Andrade Matias \\ ORCID: https://orcid.org/0000-0002-1765-5228 \\ Secretaria do Estado de Educação do Distrito Federal, Brasil \\ E-mail: klesiamatias@gmail.com \\ Zian Karla Costa-Vasconcelos \\ ORCID: https://orcid.org/0000-0002-6594-2360 \\ Universidade Federal do Tocantins, Brasil \\ E-mail: ziankarla@mail.uft.edu.br
}

\begin{abstract}
Resumo
Este artigo trata da avaliação como ato pedagógico, tendo em vista, a aprendizagem e o desenvolvimento dos estudantes. Em seu bojo, aborda-se a importância do erro como fator didático nas aprendizagens. Neste sentido, objetiva refletir sobre o erro construtivo como componente do ato pedagógico, na perspectiva da avaliação da aprendizagem. Como método, usa a pesquisa bibliográfica, na abordagem caracterizada como qualitativa. $\mathrm{O}$ estudo se justifica no intuito de responder como o erro pode ser considerado como um componente do ato pedagógico da avaliação da aprendizagem. Os resultados evidenciam que o erro construtivo, enquanto uma maneira de avaliar, se configura num dos componentes do ato pedagógico da avaliação da aprendizagem. Conclui-se como urgente a necessidade de compreender que os erros apresentados nos processos de avaliação podem ser interpretados não apenas como um termômetro para se medir quem foi melhor ou pior, mas como um ponto de partida para o avanço. Como contribuição futuras, vislumbra-se uma possibilidade de promover melhoria da aprendizagem dos estudantes, assumindo assim, uma função pedagógica.
\end{abstract}

Palavras-chave: Ato pedagógico; Avaliação da aprendizagem; Erro construtivo.

\begin{abstract}
This article deals with assessment as a pedagogical act, considering the learning and development of students. In its wake, the importance of error as a didactic factor in learning is addressed. In this sense, it aims to reflect on constructive error as a component of the pedagogical act, from the perspective of learning assessment. As a method, it uses bibliographic research, in an approach characterized as qualitative. The study is justified in order to answer how error can be considered as a component of the pedagogical act of learning assessment. The results show that constructive error, as a way of evaluating, is configured as one of the components of the pedagogical act of learning evaluation. It is concluded as urgent the need to understand that the errors presented in the evaluation processes can be interpreted not only as a thermometer to measure who was better or worse, but as a starting point for progress. As a future contribution, there is a possibility of promoting an improvement in student learning, thus assuming a pedagogical function.
\end{abstract}

Keywords: Pedagogical act; Learning assessment; Constructive error.

\section{Resumen}

Este artículo aborda la evaluación como acto pedagógico, considerando el aprendizaje y desarrollo de los estudiantes. A su paso, se aborda la importancia del error como factor didáctico en el aprendizaje. En este sentido, se pretende reflexionar sobre el error constructivo como componente del acto pedagógico, desde la perspectiva de la evaluación del aprendizaje. Utiliza como método la investigación bibliográfica, en un enfoque caracterizado como cualitativo. El estudio se justifica para responder cómo el error puede ser considerado como un componente del acto pedagógico de la evaluación del aprendizaje. Los resultados muestran que el error constructivo, como forma de evaluar, se configura como uno de los componentes del acto pedagógico de evaluar el aprendizaje. Se concluye como urgente la necesidad de entender que los errores presentados en los procesos de evaluación pueden interpretarse no solo como un termómetro para medir quién estuvo mejor o peor, sino como un punto de partida para avanzar. Como contribución futura, existe la posibilidad de promover una mejora en el aprendizaje de los estudiantes, asumiendo así una función pedagógica.

Palabras clave: Acto pedagógico; Evaluación del aprendizaje; Error constructivo. 


\section{Introdução}

Este artigo emergiu a partir das reflexões vivenciadas ao longo do segundo semestre de 2021 na disciplina "Avaliação e Gestão da Aprendizagem" e com as participações destas autoras, respectivamente, mestranda e doutoranda de um programa de pós-graduação Stricto Sensu em educação. Nessa oportunidade, foram realizados 15 encontros com apresentações de seminários em que se discutiu várias interfaces relacionadas às questões do fenômeno da avaliação. Dentre estas, ressalta-se a avaliação da aprendizagem como "ato pedagógico: o erro construtivo" que se considerou uma das temáticas emblemáticas apresentadas por suscitar debates aprofundados junto ao grupo de estudantes.

Daí, originou a proposta desse estudo voltado para discutir as ideias de autores que discorrem sobre avaliação da aprendizagem como ato pedagógico, bem como a relação com o erro construtivo. Para tal, se projeta a seguinte indagação: o erro pode ser considerado como um componente pedagógico da avaliação da aprendizagem?

No intuito de responder a esta questão problema, se tem como objetivo principal, refletir sobre o erro construtivo como componente do ato pedagógico na perspectiva da avaliação da aprendizagem.

Se justifica a realização desta investigação no intento das autoras trazerem contribuições para o campo da avaliação, sobretudo, pela importância dos docentes conceberem os erros apresentados nos processos de avaliação, não como um termômetro para se medir o melhor ou pior desempenho dos estudantes, mas como uma oportunidade para se trabalhar visando a melhoria da aprendizagem de todos(as), independente da série em que estejam cursando, pois como aponta Hoffmann (1993, p. 55) "Um professor que não avalia constantemente a ação educativa, no sentido indagativo, investigativo do termo, instala sua docência em verdades absolutas, pré-moldadas e terminais".

Diante do exposto, neste artigo, se apresenta em três tópicos do que se aborda, a saber (i) primeiro- discute avaliação como ato pedagógico, conceitos de ato pedagógico, descreve uma breve diferenciação entre avaliação da aprendizagem e avaliação para as aprendizagens; (ii) segundo - versa sobre avaliação da aprendizagem e o erro construtivo para compreensão da função pedagógica do erro, colocando-o como um elemento fundamental enquanto ponto de partida para o avanço e sinalizador do processo de construção do conhecimento; (iii) terceiro- contempla as análises das discussões realizadas, visando refletir se o erro pode ser considerado como um componente pedagógico da avaliação da aprendizagem; (iv) finaliza-se com algumas conclusões a respeito da temática abordada e referências.

\section{Metodologia}

Considerando que essa parte é de extrema relevância para o bom andamento de uma pesquisa, após refletirem sobre o tema a ser estudado as autoras definiram para o delineamento metodológico deste artigo, a abordagem qualitativa aliada à pesquisa bibliográfica.

Neste sentido, considerando que a abordagem qualitativa tem como uma das suas características o trabalho com dados em formato de textos e como salienta Teixeira (2003, p. 127) “[...] o pesquisador procura reduzir a distância entre a teoria e os dados, entre o contexto e a ação, usando a lógica da análise fenomenológica, isto é, da compreensão dos fenômenos pela sua descrição e interpretação. As experiências pessoais do pesquisador são elementos importantes na análise e compreensão dos fenômenos estudados". Nesta linha de pensamento, é que as pesquisadoras exploraram e aprofundaram as reflexões com o intuito de compreender melhor o fenômeno estudado, com base nos autores apresentados logo mais e em suas experiências como educadoras- uma com 20 anos e outra com 18 anos.

Assim, em relação aos procedimentos, a pesquisa bibliográfica norteou o melhor direcionamento a ser seguido dentro da temática, pesquisa que conforme Fonseca $(2002$, p. 32) “[...] é feita a partir do levantamento de referências teóricas já analisadas, e publicadas por meios escritos e eletrônicos, como livros, artigos científicos e páginas de web sites", o que possibilita ter uma visão do que já foi discutido sobre o tema a ser estudado e utilizar essas informações para nortear novas 
reflexões. Nessa mesma linha de raciocínio Marconi e Lakatos (2021, p. 63) endossam afirmando que a pesquisa bibliográfica “[...] não é mera repetição do que já foi dito ou escrito sobre certo assunto, mas propicia o exame de um tema sob novo enfoque ou abordagem, chegando a conclusões inovadoras".

Com base na pesquisa bibliográfica realizada, as autoras conseguiram definir o recorte da temática e contaram com um suporte teórico que direcionou suas reflexões como educadoras e com estudantes de pós-graduação. O estudo está ancorado nas seguintes obras: Demo (2001), Hoffmann (1991, 2015), Luckesi (1997, 2011, 2015), Perrenoud (1999) e Santos (2010, 2016); mas também se fundamenta em artigos mais recentes conforme é possível observar ao longo do artigo. Apoiadas nessas obras, foi possível revisitar literaturas de autores renomados e conhecer pesquisas mais recentes, aprofundando assim, a discussão sobre a relação da avaliação como componente do ato pedagógico e o erro construtivo.

\section{Resultados e Discussão}

\subsection{Avaliação como ato pedagógico}

Notadamente, ao revisitar as formas de se fazer avaliação é pertinente esclarecer o significado expresso do ato pedagógico que compõe os processos de ensino e das aprendizagens. Assim, Luckesi (2015) conceitua o ato pedagógico que se concretiza por diferentes maneiras no avaliar, planejar e executar, desde o momento inicial da elaboração dos planejamentos pelos professores ao detalhar as atividades em cada aula a ser ministrada. Esta previsão, pode ser iniciada com uma atividade diagnóstica que servirá para se planejar com base nos conhecimentos adquiridos pelos alunos. Este autor, alerta para a necessidade de pensar que o ato de avaliar não deve estar dissociado do pedagógico e visto como uma obrigação de final do mês ou do bimestre, em que se dispõe de tempo para atribuir notas aos alunos se aprenderam os conteúdos medidos por provas.

Em outra análise, Luckesi (1997) identifica três elementos que compõem o ato pedagógico com implicações futuras por buscas de desejos relacionados aos objetivos almejados dentro do processo ensino- aprendizagem.

Reitera,

[...] importa saber qual o desejo com ação pedagógica que praticamos junto aos educandos e se queremos estar entregues a ele, a fim de que possamos construir os resultados satisfatórios com o auxílio do planejamento, execução e avaliação, auxiliando o desenvolvimento dos educandos, ao mesmo tempo que processamos nosso auto crescimento. (Luckesi, 1997, p.167)

Nessa compreensão fundamentada do ato pedagógico, alude-se que o ato de avaliar compõe um dos elementos imprescindíveis dentro dos processos ensino-aprendizagem. Contudo, divide opiniões no que tange às diversas maneiras de se conceber e conduzir tal processo. Em outra acepção, acrescenta-se na atualidade, que se vive numa sociedade plural e exigente em relação às questões com abrangências sobre ato de avaliar e se torna um dever repensar em prol dos estudantes oriundos de diversos contextos sociais e participantes desse processo. Para isto, deve-se retomar as reflexões originadas dos objetivos desejados a serem alcançados por meio de avaliações dentro do processo ensino-aprendizagem.

De tudo, Luckesi (2015) prognostica que a proposta de avaliação está relacionada à investigação da qualidade de alguma coisa e varia conforme o objeto vinculado à aprendizagem escolar. Opina, ser necessário comparar o que será avaliado com reflexos na qualidade da aprendizagem. Ora o que se pretende avaliar, para esse autor implicará na qualidade da aprendizagem dentro das escolas ao aferir o desenvolvimento do conhecimento do aluno.

Sobre isto, é importante refletir sobre o que está posto, considerando que vive- se em uma sociedade positivista e exige resultados altos. Conquanto, apesar das pressões sociais, a escola não pode perder de vista um dos seus papéis dentro do processo ensino- aprendizagem, ou seja, formar pessoas com qualidade para uma sociedade democrática. No entanto, emergem os questionamentos: como fazer isso? É possível, seguir a mesma linha nas formas de avaliar? 
Outro ponto de atenção da avaliação remete às pessoas que não aprendem de maneira igual, pois possuem formas diferentes de compreensão e tempos de assimilação. Logo, não seria justo avaliar "todos" da mesma forma, pela existência de variáveis externas que podem influenciar no desempenho de um aluno em um dia específico. Mesmo em condições semelhantes, os resultados seriam diversificados devido ao tempo de cada um. Por isso, a necessidade de se diversificar os instrumentos de avaliação para que ocorra ao longo do processo.

Além do mais, é preciso levar em conta que o olhar avaliativo é interpretativo, ou seja, possui caráter subjetivo, tendo em vista que por meio da avaliação o professor revela suas concepções teóricas e suas percepções individuais acerca do desenvolvimento dos estudantes. Nesse sentido Hoffmann (2015, p. 86) aponta que "A avaliação parte sempre da interpretação do que se vê. Envolve as percepções, os sentimentos, as experiências anteriores e os conhecimentos de quem avalia". Nessa perspectiva, não há como fugir do caráter subjetivo da avaliação pois corre-se o risco de desvirtuá-la de sua finalidade que deve ser compreendida como um ato de reflexão e de tomada de decisão de cada avaliador. Assim "O caminho então, é estarmos conscientes desse caráter interpretativo do processo, porque passaremos a duvidar de nossas certezas e hipóteses, levando novas perguntas sobre o que se vê, e não respostas definitivas” (Hoffmann, 2015, p. 87).

Pensando em respostas para os questionamentos elencados, se desvela a avaliação como um componente do ato pedagógico, em contrário de instrumento utilizado de punição ou classificação como auxiliar no processo de desenvolvimento da aprendizagem. Acerca disso, Paulo Freire (1998, p.52) justapõe que as escolas e professores estejam cientes "Saber que ensinar não é transferir conhecimento, mas criar possibilidades para a sua própria produção ou a sua construção". Credita na perspectiva do ato de avaliar, ajuda aos alunos no processo de construção das aprendizagens.

Para melhor entendimento tomou-se como base o pensamento de Luckesi (1997) para sintetizar os processos avaliativos de aprendizagem com suas principais características e que sugerem as consequências entre exame e avaliação. A seguir, no Quadro 1:

Quadro 1: Diferenças entre Avaliação e Aprendizagem.

\begin{tabular}{|l|l|}
\hline \multicolumn{1}{|c|}{ Avaliação } & Exame \\
\hline Amorosa & Não é amoroso \\
\hline Inclusiva & Excludente \\
\hline Oportunidade de aprendizagem significativa & $\begin{array}{l}\text { Oportunidade de prova de resistência dos alunos aos ataques } \\
\text { do professor }\end{array}$ \\
\hline Construtiva & Não é construtivo \\
\hline Busca o melhor de todos & Seleciona, classifica \\
\hline Ensino centrado na aprendizagem significativa & Ensino centrado nos resultados das provas e dos exames \\
\hline $\begin{array}{l}\text { Prática pedagógica voltada para uma pedagogia do } \\
\text { ensino/ aprendizagem }\end{array}$ & Prática pedagógica voltada para uma pedagogia do exame \\
\hline $\begin{array}{l}\text { Relação professor- aluno: entre pessoas } \\
\text { Liberdade }\end{array}$ & $\begin{array}{l}\text { Relação professor- aluno: passa a ser relação entre coisas- } \\
\text { as notas }\end{array}$ \\
\hline Espontaneidade, busca & Submissão \\
\hline Travessia permanente em busca do melhor & Medo \\
\hline Provas para diagnosticar & Chegada definitiva \\
\hline $\begin{array}{l}\text { Pedagogicamente: auxilia na construção da } \\
\text { aprendizagem satisfatória }\end{array}$ & Provas para reprovar \\
\hline $\begin{array}{l}\text { Psicologicamente: desenvolve personalidade } \\
\text { criativas e livres }\end{array}$ & $\begin{array}{l}\text { Pedagogicamente: centraliza a atenção nos exames e não } \\
\text { auxilia na aprendizagem dos estudantes }\end{array}$ \\
\hline $\begin{array}{l}\text { Sociologicamente: é útil para os processos de } \\
\text { inclusão social. }\end{array}$ & $\begin{array}{l}\text { Psicologicamente: é útil para desenvolver personalidades } \\
\text { submissas }\end{array}$ \\
\hline & $\begin{array}{l}\text { Sociologicamente: é útil para os processos de seletividade } \\
\text { social. Avaliação está muito mais articulada com a } \\
\text { reprovação do que com a aprovação e daí vem a sua } \\
\text { contribuição para a seletividade social }\end{array}$ \\
\hline
\end{tabular}


No Quadro 1, se visualiza a dicotomia das proposições entre exame e avaliação. Verifica-se em cada tipo de concepção que pode atender aos diferentes objetivos dentro do processo ensino- aprendizagem. Nota-se que todas as questões não se limitam aos parâmetros certo ou errado, mas produzem contribuições para potencializar as aprendizagens dos estudantes.

Desse ideário, sedimenta-se que a avaliação chamada formativa ocorre por meio do auxílio e com condições que viabilizem melhorias didático-pedagógicas no desenvolvimento do aprendizado de cada educando.

Por esta ótica, enuncia-se como sendo aquela que pretende perceber as dificuldades dos alunos, organizando uma intervenção pedagógica com possibilidades de previsões dos avanços. Em corroboração Santos, (2010, p. 12) visiona, “[...] o seu objetivo é acima de tudo ajudar a compreender o funcionamento cognitivo do aluno face a uma dada situação proposta para se poder intervir de forma adequada ", é uma avaliação que corrobora para uma formação pessoal e social.

Concernente à avaliação das aprendizagens Santos (2016, p. 641) compara ser bastante relacionada à avaliação somativa, explica "[...] interessa em sumarizar o que o aluno aprendeu ou não, o que sabe ou não, o que é ou não capaz de fazer, no momento final de um ciclo de aprendizagem [...]".

Vale destacar, apesar de ser o ideal uma avaliação para as aprendizagens e não das aprendizagens, porém é importante esclarecer: “[...] o processo de avaliação predominante é a avaliação das aprendizagens, isto é, a avaliação que se caracteriza como o estabelecimento de hierarquias acerca do desempenho dos estudantes [...]" (Bolzan, Fernandes e Antunes, 2019, p. 379).

\subsection{Avaliação da aprendizagem e o erro construtivo}

Com consultas ao dicionário on-line Infopédia (2021), detecta-se que a palavra 'erro' pode ser compreendida dentre os sentidos semânticos, como sendo: decisão, ato ou resposta incorreta; qualidade daquilo que não corresponde à verdade; engano; apreciação ou julgamento que está em desacordo com a realidade observada; juízo falso; falta; culpa.

Estas definições, segundo Luckesi (1997, p. 54.) refletem a herança da cultura "ocidental-cristã" e de sua concepção filosófica-religiosa, em que o erro é visto como pecado e merece ser castigado. Para além disso, identifica que na nossa sociedade refletem os conceitos herdados de uma sociedade burguesa e como a escola reflete a sociedade, ainda hoje, prevalece a prática de avaliação direcionada pela pedagogia tradicional. Em função disso, auspica que reduz as melhorias nas práticas avaliativas por meio das provas e exame com características discriminatórias, excludentes, autoritárias, punitivas, que levam a culpabilização, a julgamentos arbitrários e sem sentidos.

Luckesi (1997, p. 48) frisa que a ideia de erro “[...] só emerge no contexto da existência de um padrão considerado correto". Ratifica que essa visão cartesiana é equivocada na retórica de que "onde existe erro não existe acerto" onde a responsabilidade sobre a aprendizagem é totalmente do aluno, eximindo o professor de toda a culpa. Situa que, mudar o olhar sobre o erro consiste em compreender que o erro só existe imbuído de um padrão a ser seguido, muitas vezes, definido de forma arbitrária por alguém.

Em contrapartida para superar essa visão tradicional Luckesi (1997, p. 48) argumenta que a mesma "[...]tem conduzido ao uso permanente do castigo como forma de correção e direção da aprendizagem, tomando a avaliação como suporte de decisão". Delimita que ao longo da história, a origem do entendimento do erro passou a ser transformado em variadas formas de castigo ao expor estudantes e os colocar numa posição de culpados, pelo fato de não terem conseguido aprender.

De todo modo, o erro sob a ótica da avaliação formativa, de acordo com Perrenoud (1999, p. 78) passa ser compreendida como "[...] toda avaliação que ajuda o aluno a aprender e a se desenvolver, que participa da regulação das 
aprendizagens e do desenvolvimento no sentido de um projeto educativo." Nessa perspectiva, a avaliação é concebida como um espaço de diagnóstico, intervenção, problematização e ação a serviço das aprendizagens de todos.

Nesta direção, Luckesi (1997) prediz que a avaliação se consolida num processo contínuo nas possibilidades de verificar a constituição do erro em sua origem, assim como superá-los com benefícios significativos para estudantes e professores. Como proposição, este autor defende que o professor deve aceitar o erro do estudante como um indicador de que algo no processo ensino-aprendizagem não saiu como planejado. Por isso, mostra a importância da avaliação como um processo contínuo, pois verificar a constituição do erro e sua origem nos dá possibilidade de superá-los com benefícios significativos para o crescimento pessoal. Infere-se que, enquanto educadores, precisamos transcender a visão do erro como insucesso do aprendizado para que o mesmo, possa ser considerado como uma oportunidade para reorientação do trabalho, um trampolim em busca de um melhor caminho, tornando-se assim, uma fonte de crescimento tanto para professores como para estudantes.

Nessa perspectiva, Hoffmann (1991) aponta que o erro apresenta um grande potencial educativo, tendo em vista que, ao considerar os erros dos estudantes, além de se comprometer com a melhoria do aprendizado o professor tem a possibilidade de repensar a sua prática pedagógica. Para tanto, a autora ressalta que o professor precisa compreender e identificar os erros cometidos pelos estudantes, para a partir daí fornecer condições para superá-los, ou seja, não basta identificar o erro, é preciso redimensionar a sua concepção para que assim ele possa ser transformado em algo positivo.

Na interpretação de Demo (2001, p. 50) “O erro não é um corpo estranho, uma falha na aprendizagem. Ele é essencial, é parte do processo. Ninguém aprende sem errar." Com efeitos, fomenta que se deve promover mudanças do olhar tradicional do erro visto como um problema e visionar o princípio de uma nova aprendizagem.

Na mesma lógica de pensamento, Nogaro e Granella (2004, p. 6) sinalizam,

O "erro" deve ser considerado como uma forma construtiva do saber, como uma fonte de crescimento, e não como uma ferramenta de exclusão. Cabe à escola, ao professor, como meios diretos da formação de identidade críticas e não conformidades, dar o passo maior em busca de uma educação que valorize as vivências de cada uma e que tenha por objetivo primeiro a conscientização do ser humano, enquanto ser social, da importância que cada um tem na formação de uma sociedade mais justa, menos excludente e mais interessada no ser, não no fazer.

A noção construtiva do erro retoma as possibilidades de rompimentos com práticas avaliativas sistematizadas a partir dos séculos XVI e XVII numa vertente centrada nas formas tradicionais de conceber e conduzir a ação pedagógica.

Em consonância, Luckesi, (2011) norteia que esse ideário se concretizou dentro de um modelo teórico que pressupõe a educação como um mecanismo de conservação e reprodução da sociedade, ou seja, a serviço de um modelo social dominante. Denota que para avaliação assumir o seu papel de instrumento dialético e diagnóstico, recomenda situá-la em outro contexto pedagógico, colocar a serviço de uma pedagogia que esteja preocupada com democratização do ensino, trabalhe para a superação do autoritarismo e a favor do desenvolvimento da autonomia do educando.

Para estas ações, Luckesi (2011, p. 177) explica

Uma prática educativa que tem a avaliação como seu recurso subsidiário de construção dos resultados desejados deve estar fundada na crença de que todo educando aprende e, por aprender se desenvolve. Isto implica investimento cotidiano em sua aprendizagem. Nesse caso as dificuldades não deverão ser fonte de desânimo, mas sim desafios que convidam o educador a investir mais e mais nos educandos. Com investimento todos aprendem e se desenvolvem.

Chama atenção o ressignificar da visão do erro, pois considerá-lo como parte do processo de aprendizagem, certamente, abrange a forma construtiva. Vale ressaltar que o erro não é necessário para o crescimento do aluno, mas deve ser inserido como parte para os avanços intelectuais e nos conhecimentos. Assim, Luckesi (1997, p. 59) reafirma: "uma vez que 
ocorram, não devemos fazer deles fontes de culpa e de castigo, mas trampolins para o salto em direção a uma vida consciente, sadia e feliz".

Destarte, refletir sobre o erro como uma fonte de crescimento importante para estudantes e professores. Segundo Esteban (1999, p. 21) "O erro oferece novas informações e formula novas perguntas sobre a dinâmica aprendizagem/desenvolvimento, individual e coletiva". Destas percepções, Esteban (1999) expressa que muitas vezes o erro revela mais que o acerto, pois coloca o saber numa perspectiva processual, indicando o que o estudante sabe, o que não sabe e o que pode vir a saber. Para este autor, os erros podem e devem constituir-se como elementos norteadores das ações e intervenções pedagógicas, desencadeando reflexões, intervenções e reorganização do trabalho docente.

Nessa perspectiva, Santos Júnior e Barboza (2020, p. 14) sinalizam que "Compreender causas e motivações do erro do aluno constitui-se num dos pilares que pode ajudar a melhorar o processo de ensinar do professor e a aprendizagem do aluno". Assim, no que tange conceber o erro como construtivo se converte num crivo para se compreender como um elemento constitutivo da aprendizagem, que pode e deve ser utilizado como uma ferramenta na construção de hipóteses de conhecimentos, tendo em vista, o respeito e a valorização da perspectiva dos estudantes. Ademais, deve proporcionar reflexões sobre a prática pedagógica do professor, à medida que oportuniza a avaliação e a reorientação de sua práxis, tomando como base as necessidades dos estudantes. Ressignificar o conceito de erro, implica em avanços nas concepções de avaliação como coloca Luckesi (2011, p.294), “[...] os atos avaliativos de acompanhamento e de certificação da aprendizagem serão nossos efetivos aliados na obtenção do sucesso nos resultados e na democratização do ensino".

\subsection{O erro pode ser considerado como um componente pedagógico da avaliação da aprendizagem?}

As contribuições teóricas utilizadas neste trabalho buscam refletir sobre o erro construtivo como componente do ato pedagógico na perspectiva da avaliação da aprendizagem. Nesse sentido, buscou-se sistematizar contribuições trazidas por alguns pesquisadores acerca da necessidade de repensar o significado da avaliação da aprendizagem, sob a perspectiva de tornar esse processo coletivo e plural de modo a proporcionar espaços de diálogo que rompam com a lógica do exame utilizado na escola tradicional, sob o paradigma positivista.

Pelo exposto, neste artigo, relaciona-se que a avaliação define um papel importantíssimo ao romper com a visão tradicional de avaliação classificatória, em que o ato avaliativo se transforma em mérito, julgamento, punição e recompensa. Isto ocorre, quando uma avaliação é proposta visando promover as aprendizagens de todos, constituindo-se assim, como um espaço democrático de reciprocidade, emancipação e promoção das aprendizagens (Luckesi, 1997, 2011, 2015). Seguindo essa lógica, Alves et al. (2020, p. 15) reforçam a importância de posicionar a avaliação como "[..] um instrumento a favor da aprendizagem do aluno". Nessa perspectiva, ela é compreendida como um processo cíclico, que permite ao professor redirecionar as suas ações possibilitando o desenvolvimento do estudante.

Neste contexto, faz-se necessário compreender a avaliação e o planejamento como atos indissociáveis, pois sua execução está a serviço da construção de conhecimento pelos estudantes. Fomenta-se, enquanto o planejamento traça os futuros caminhos a serem percorridos, a avaliação ajuda no redirecionamento do percurso da ação. Nesses termos, Lourdes, Gomes e Carvalho (2020) salientam a relevância da avaliação diagnóstica como uma importante ferramenta que possibilita a reflexão sobre os processos de ensino e aprendizagem. Assim, entende- se que o ato de planejar, executar e avaliar, funcionam como recursos fundamentais no processo de ensino e aprendizagem por direcionarem os caminhos da ação pedagógica, com vistas à construção de saberes.

Não obstante, a avaliação da aprendizagem precisa ser vista como um ato amoroso e se manifesta de forma a acolher os atos e ações reais, sem julgamentos. Além disso, deve oportunizar a inclusão e a integração ao oferecer para os estudantes um apoio para ampliar suas aprendizagens e escolher caminhos próprios, centrando-se na aprendizagem significativa e na 
democratização do ensino. Desta perspectiva, emerge a seguinte pergunta: o erro pode ser considerado como um componente pedagógico da avaliação da aprendizagem?

A este respeito, as discussões apontam para a importância de se compreender o erro como parte do processo ensinoaprendizagem e consequentemente como uma oportunidade para construir conhecimento a partir dos saberes construídos pelos estudantes, pois como aponta Silva $(2008$, p. 102) a virtude do erro “[...] está na possibilidade de constituir-se em fonte de crescimento, para alunos e professores, uma vez que permite o reconhecimento de sua origem e dos procedimentos e mecanismos que o produziram".

Sob essa perspectiva, o erro passa a ser considerado como um ponto de partida para a tomada de decisões com vistas aos ajustes necessários, seja no planejamento do professor ou nos processos que envolvem as aprendizagens dos estudantes, constituindo- se como uma rica fonte de aprendizagem e desenvolvimento, favorecendo o crescimento de todos os envolvidos no processo (Demo, 2001).

Daí, pode-se entender o erro como construtivo quando utilizado para reorientar a prática docente de modo a conhecer os interesses, os saberes, as fragilidades e as potencialidades dos estudantes, ao mesmo tempo que promove indicações claras acerca do que é necessário fazer para avançar. Nessa perspectiva Abrahão (2007, pp. 196-197) aponta que

O papel do professor na perspectiva do erro construtivo é fundamental no sentido de respeitar e valorizar os conhecimentos que o aluno traz para, partindo destes, desencadear reflexões para que a criança possa evoluir e constituir novas hipóteses para a solução de um problema. Além disso, valorizando o conhecimento do aluno e partindo das hipóteses construídas por ele e das dificuldades por ele encontradas, o professor poderá planejar a ação pedagógica no sentido de intervir neste processo como mediador entre o conhecimento atual e o novo conhecimento que a criança poderá elaborar.

Assim, o papel do professor é fundamental, tendo em vista que ele é o responsável por orientar os estudantes e estimular suas tentativas, fazendo-o refletir e assim progredir em seus conhecimentos.

Por fim, considera- se que educação abordada em contextos democráticos, ressignifica o papel da avaliação, consequentemente da visão do erro, na busca de oportunizar o desenvolvimento dos estudantes, valorizar seus saberes, impulsionando-os a superar suas dificuldades de forma contextualizada, humanizada e sensível.

\section{Conclusão}

De tudo, tem-se a crença de que a avaliação é um componente importante do ato educativo e do processo de aprendizagem. Por conseguinte, Luckesi (2011, p. 264) sedimenta que pode ser definida como "[...] uma atribuição de qualidade, com base em dados relevantes da aprendizagem dos educandos, para uma tomada de decisão". Sendo assim, deverá ser capaz de dialogar com a multiplicidade e pluralidade de conhecimentos que os estudantes apresentam.

Infere-se, que enquanto educadores, precisamos transcender a visão do erro como insucesso do aprendizado, para que o mesmo possa ser considerado como um ponto de partida para o avanço, uma oportunidade para reorientação do trabalho, um trampolim em busca de um melhor caminho, tornando-se assim uma fonte de crescimento, tanto para professores como para estudantes.

À luz dessa ótica, se entende que ao ressignificar o papel do erro nas práticas avaliativas, é empreendido um passo largo para romper com a visão tradicional da escola classificatória e excludente, para comprometer-se com uma escola dialógica, acolhedora, reflexiva, construtiva, inclusiva, ou seja, verdadeiramente democrática.

Em suma, fomenta-se ser compreensível delegar aos educadores reconhecerem o processo de avaliação da aprendizagem como mediadora da prática docente, para que o erro seja concomitante ao ato pedagógico e redimensionado num processo de construção dos saberes. 
Como desdobramentos para futuros estudos, este artigo aponta para a necessidade de realização de estudos empíricos que corroborem para que se repense os processos avaliativos a partir da ressignificação do erro, tornando-o uma ferramenta para potencializar as aprendizagens dos estudantes. Assim, nuanças que envolvem as especificidades dos diversos atores envolvidos nos processos avaliativos de aprendizagem, assim como o contexto social em que estão imersos, apontam realidades diferentes, com necessidade específicas, fatores que por si só apontam para a necessidade da realização desse tipo de estudo de forma a garantir o que de fato se almeja através da avaliação, a superação de dificuldades- aprendizagem.

\section{Referências}

Abrahão, M. H. M. B. (2007). Estudos sobre o erro construtivo - uma pesquisa dialógica. Educação, 30(4). Recuperado em 5novembro, 2021, de https://revistaseletronicas.pucrs.br/index.php/faced/article/view/3557

Alves, P. T. de A., Oliveira, S. do A., Jucá, S. C. S., e Silva, S. A. da. (2020). Avaliação diagnóstica como estratégia para o aumento da proficiência em Língua Portuguesa. Research, Society and Development, 9(8), e449985480. https://doi.org/10.33448/rsd-v9i8.5480

Bolzan, L. M.; Fernandes, D. e Antunes, E. D. (2019). Concepções avaliativas no ensino superior de administração. Revista Cesgranrio, 11(32), 376-405. https://revistas.cesgranrio.org.br/index.php/metaavaliacao/article/view/1998

Demo, P. (2001, agosto). Papel do Erro. Revista Nova Escola, 144, seção fala mestre, 49- 51.

Esteban, M. T. (org.). (2004). Avaliação: uma prática em busca de novos sentidos. DP\&A.

Fonseca, J. J. S. (2002). Metodologia da Pesquisa Científica. UEC.

Freire, P. (1998). Pedagogia da Autonomia: saberes necessários à prática educativa (8a ed.). Paz e Terra.

Hoffmann, J. (1991). Avaliação: Mito e Desafio. uma perspectiva construtivista (11a. ed.). Mediação.

Hoffmann, J. (1993). Avaliação Mediadora. Uma prática em construção da Pré-escola à Universidade. Porto Alegre: Educação e Realidade.

Hoffmann, J. (2015). Avaliação e Educação infantil: um olhar sensível e reflexivo sobre a criança (20a ed.). Mediação.

Infopédia, Erro. (2020) Portal Eletrônico Dicionário Porto editora. https://www.infopedia.pt/dicionarios/lingua-portuguesa/erro.

Lakatos, E. M. e Marconi, M. A (2021). Técnicas de pesquisa (9a ed.). Atlas.

Lourdes, D. F. de, Gomes, A., \& Carvalho, E. T. de. (2020). Intervenção pedagógica: um trabalho visando a qualidade no processo de ensino-aprendizagem. Research, Society and Development, 9(4), e58942840. https://doi.org/10.33448/rsd-v9i4.2840

Luckesi, C. C. (2011). Avaliação da Aprendizagem Componente do Ato Pedagógico. Cortez.

Luckesi, C. C. (2015). Avaliação da Aprendizagem: componente do ato pedagógico (2a ed.). Cortez.

Luckesi C. C. (1997). Avaliação da Aprendizagem Escolar (6a ed.). Cortez.

Nogaro, A. e Granella, E. (2004). O erro no processo de ensino e aprendizagem. Revista de Ciências Humanas, 5(5), 31-56. Recuperado em 10 agosto, 2021, de http://revistas.fw.uri.br/index.php/revistadech/issue/view/43.

Perrenoud, P. (1999). Avaliação da Excelência à Regulação das Aprendizagens: entre duas lógicas. Artes Médicas.

Santos Júnior, J. F. dos, e Barboza, P. L. (2020). Como o professor de Matemática percebe o erro do aluno resolvendo atividades matemáticas. Research, Society and Development, 9(8), e246985290. https://doi.org/10.33448/rsd-v9i8.5290

Santos, L. (Org.). (2010). Avaliar para Aprender: relatos de experiências de sala de aula do pré-escolar ao ensino secundário. Porto Editora.

Santos, L. (2016). A articulação entre a avaliação somativa e a formativa, na prática pedagógica: uma impossibilidade ou um desafio? Ensaio: Avaliação $e$ Políticas Públicas em Educação, 24(92), 637 - 669. https://www.scielo.br/j/ensaio/a/ZyzxQhwSHR8FQTSxy8JNczk/?format=pdf\&lang=pt Aces

Silva, E. M. D. da (2008). A virtude do erro: uma visão construtiva da avaliação. Estudos Em Avaliação Educacional, 19(39), 91-114. https://doi.org/10.18222/eae193920082471

Teixeira, E. (2003). As Três Metodologias (6a ed.). UNAMA. 